\title{
A CLOUD COMPUTING MODEL FOR OPTIMIZATION OF TRANSPORT LOGISTICS PROCESS
}

\author{
Zineb Benotmane ${ }^{1}$, Ghalem Belalem ${ }^{2}$, Abdelkader Neki ${ }^{3}$ \\ ${ }^{1,2}$ Department of Computer Science, \\ Faculty of Exact Sciences and Applied, \\ University of Oran 1, Ahmed Ben Bella, Oran, Algeria \\ E-mail: benotmane.dz@gmail.com \\ E-mail: ghalem1dz@gmail.com \\ ${ }^{3}$ IUT de Cergy Pontoise \\ QLIO Department, \\ 95-97, rue Valère Collas \\ 95100 Argenteuil. Paris, France \\ E-mail: abdelkader.neki@u-cergy.fr
}

\begin{abstract}
In any increasing competitive environment and even in companies; we must adopt a good logistic chain management policy which is the main objective to increase the overall gain by maximizing profits and minimizing costs, including manufacturing costs such as: transaction, transport, storage, etc. In this paper, we propose a cloud platform of this chain logistic for decision support; in fact, this decision must be made to adopt new strategy for cost optimization, besides, the decision-maker must have knowledge on the consequences of this new strategy. Our proposed cloud computing platform has a multilayer structure; this later is contained from a set of web services to provide a link between applications using different technologies; to enable sending; and receiving data through protocols, which should be understandable by everyone.

The chain logistic is a process-oriented business; it's used to evaluate logistics process costs, to propose optimal solutions and to evaluate these solutions before their application.

As a scenario, we have formulated the problem for the delivery process, and we have proposed a modified Bin-packing algorithm to improve vehicles loading.
\end{abstract}

Keywords: Cloud Computing, sustainable logistics, web service, optimization algorithm, Bin-packing algorithm, logistics process, First-fit algorithm, delivery process

\section{Introduction}

Nowadays, optimization of the supply chain aims to reduce related costs with pollution to have increasing profits and assuring safety. Several decisions must be made at different levels to improve the chain.

It is in the context of optimization and decision support for supply chain management that this paper takes part.

The supply chain management is a complex task which is associated with decision making in all levels: from the chain design stage to its operational functioning. All these decisions will have an impact within a defined period of time. This is why, three timing levels with which decisions are associated, are defined: strategic, tactical and operational level. These levels should have an impact in the long, medium and short term respectively (Carrera et al., 2010a; Carrera et al., 2010b).

The strategic level considers decisions that have a long term impact on the organization. This includes decisions on the number, location and capacity of warehouses and production facilities, the choice of partners, the organization of flows within the logistics network, etc. The tactical level includes decisions that are reconsidered periodically, with periods ranging from a few months to a year, for example: procurement decisions and production planning, storage policies, transportation strategies and also the customer visit frequency. Finally, the operational level focuses on everyday decisions, such as scheduling, resource allocation, identification of delivery, routing, truck loading, etc.

Considering the operational decision-making level, the objective of this paper is to provide a cloud platform of logistics chain for decision support aiming three challenges:

- Evaluate a logistics process costs;

- Propose optimal solutions;

- Evaluate these proposed solutions. 
Our proposed approach based on cloud computing platform has a multilayer structure, and is composed of a set of web services to provide a link between applications using different technologies and to enable sending and receiving data through protocols understandable by everyone.

In order to test the efficiency of this approach, we have chosen to optimize the delivery process by reducing related costs, the results obtained show that the use of an optimization algorithm for loading trucks reduces the delivery costs.

The rest of the page is structured as follows:

- In the 2nd section, we present some related works.

- In the 3th section, we describe the detail of the suggested approach based on Cloud Computing and its functional architecture.

- In the 4th section, we describe the scenario of study case and we present the different results.

- Finally, we conclude our work by some extensions which we will consider in the future.

\section{Related Works}

Procurement, warehouse and transportation management systems optimize the supply chain, however, several challenges appear for logistics service providers since their customers require individualized services with flexibility, transparency cost and performance, massive demand for resources, resource variation, a claim for calculation and short-term contracts. These requirements lead many logistics service providers to the following problems:

- Lack of investment funds for the extension of IT.

- $\quad$ Lack of IT expertise.

- Insufficient human resources to operate necessary IT.

- Difficulty of developing new IT components and their integration into the existing.

Nowadays, many professionals in logistics sector see in the Cloud Computing a new tool to optimize their processes, sometimes as individual applications but also as complete software solutions, all hosted in the Cloud. This is a concept where IT resources are virtualized and dynamically elastic; these resources are provided as a service over the Internet, transparently to users. The concept includes Infrastructure as a Service (IaaS), Platform as a Service (PaaS) and Software as a Service (SaaS).

The use of specific logistic cloud services is therefore regarded as a viable solution that is based on the paradigm "everything is service", and here are some reasons for which it would be interesting to apply cloud computing to manage the supply chain:

- Software in cloud included free versions.

- Companies invest in a monthly / annual charge relatively low, moreover, they can have access to the latest hardware platforms and better solutions without the need to consider the cost of assessing the hardware and software for the reason that in cloud "you pay what you use".

- The cloud computing enables small and medium enterprise to have access to professional solutions with less IT investments.

- Through applications as services offered by a cloud, companies can significantly reduce the number of IT professionals and technical personnel.

- Internal IT professionals could place more energy and time in the development of critical applications in the heart of the trade.

- Logistics systems based on cloud computing also allow better collaboration, better monitoring of the supply chain and provide better services for customers.

In the first part of this section, we discuss some works have integrated cloud computing in the logistics context to justify our choice that has brought to this technology, and in the second part, we review other works that handled the environmental aspects of the supply chain.

\subsection{Cloud Computing in service of logistics}

There are various existing definitions of Mobile Cloud Computing; commonly, the term mobile cloud Logistics is able to pilot physical flows through to information flows, and consequently, a set of 
tools and technology solutions for the informational management of products throughout the supply chain has been implemented and proposed by logistics service providers, we cite among these solutions some systems and software such as ERP (Enterprise Resource Planning), WMS (Warehouse Management System), TMS (Transportation Management Systems), reviewed in (Nettstrater et al., 2014). ERP software packages are systems that aim to coordinate all the activities of a company around a common information system, the most important decisions are made in ERP, they are then sent to other systems such as WMS or TMS. In (Nettstrater et al., 2014) authors have listed key functions and extended functions of each software package, and have proposed a task model encompassing all logistics activities with the IT support for supply chain management.

Nowadays, many professionals in logistics sector see in the Cloud Computing a new tool to optimize their processes. Sometimes as individual applications but also as complete software solutions, all hosted in the Cloud. However, despite advantages offered by the use of cloud computing in logistics, opinions are still divided: Is Cloud a real promising concept, which allows better economizing and responding to change and to limit restrictive investment? Or conversely, are security, performance and availability really guaranteed? to answer these questions, authors in (Subramanian et al., 2014) have developed and tested a conceptual model to examine the environmental and economic benefits of the integration of "logistics service providers of small and medium enterprises (SMLSPs)" and "cloud computing service providers" in the same Chinese context, this model measures the need to adopt Cloud Computing by logistics service providers, by using statistical techniques such as factorial analysis. For this statistical study, employees from different departments of different companies were answered on questionnaires, the questions focused on the economic and environmental benefits of adopting cloud computing, and the responses were evaluated on the scale Likert basis of five points.

The Fraunhofer Institutes for Material Flow and Logistics (IML) and for Software and System Technology (ISST) created in 2012 the Logistics Mall which is a kind of online application supermarket, these new platforms were described in (Daniluk and Holtkamp, 2014) and (Holtkamp, 2014). The principle of the Logistics Mall is to combine several logistics applications, such as warehouse management applications with inventory applications connected at customs for the needs of a particular client company, each of these applications is offered by a provider logistics application and hosted in the logistics Centre.

In (Li et al., 2012; David et al., 2015) authors present a cold chain logistics system based on cloud computing whose functions are: real-time monitoring of cold chain logistics, data calculation, logbook recording, query, generating reports and so on. Authors take the distribution model of the cloud calculating system as an example.

In (Chow et al., 2007) an intelligent system called logistics process knowledge-based system is presented, the aims of which are: to describe the real-time status of process environments through diagnosing multiple real-time data/information sources, to address potential problems within logistic processes, to deliver logistic process procedures (explicit knowledge) and logistic process logic (tacit knowledge) to staff members who are orchestrating and performing various logistics processes satisfactorily in real time, and, to provide information of real-time logistics process progress status, thereby helping logisticians systematically to manage logistics processes and resources effectively.

\subsection{Sustainable Logistics}

Formerly, strategic decisions in logistics were taken to reduce costs and improve service quality, considering only the economic aspect. At present, these decisions are taking a green curve by considering, in addition to economic aspect, the ecological aspect.

Inspired by research on performance measurement, in (Boukherroub et al., 2015), authors designed a method that links sustainability performance to supply chain decisions, and allows setting coherent performance measures, then they transposed this method to a multi-objective mathematical programming to optimize the supply chain planning while the economic, environmental and social performances are all coherently integrated into the model. To illustrate their approach, they applied it to a Canadian lumber industry case.

In (Abduaziz et al., 2014), authors tried to assess green logistics practices in automotive industry by using simulation method. The proposed model will assist decision makers acquire an in-depth understanding of environmental impacts and costs associated. 
In this paper, we propose a cloud computing platform for logistics with a multilayer structure; it is composed of a set of web services aiming three challenges:

- Evaluate a logistics process costs;

- Propose optimal solutions;

- Evaluate these proposed solutions.

\section{Proposed Approach}

The principle of supply chain management is to deliver "the right product in the right quantity to the right place at the right time and with minimal cost" (Neven, 1989). To achieve this, the company must adopt a good logistics chain management policy whose main objective is to increase the overall gain by maximizing profits and minimizing costs, including manufacturing, transaction, Transportation, storage, etc.

Decisions must be made to adopt a new strategy for cost optimization; however, the decisionmaker must have knowledge on the consequences of this new strategy. Our approach simulates a new policy and allows the decision maker to view the corresponding costs.

We propose in this paper a cloud computing platform with a multilayer structure; it is composed of a set of web services to provide a link between applications using different technologies which enable sending and receiving the data through protocols understandable by everyone. In addition, our cloud environment is private, so the provider of this environment guarantees to verify in a profound way (according to the requirements mentioned in the Service Level Agreement contact) all aspects of security, in addition to communication between clients within the Cloud Computing are provided by a network of the Virtual Private Network (VPN) type.

Figure 1 represents our cloud computing platform for optimizing a logistics process.

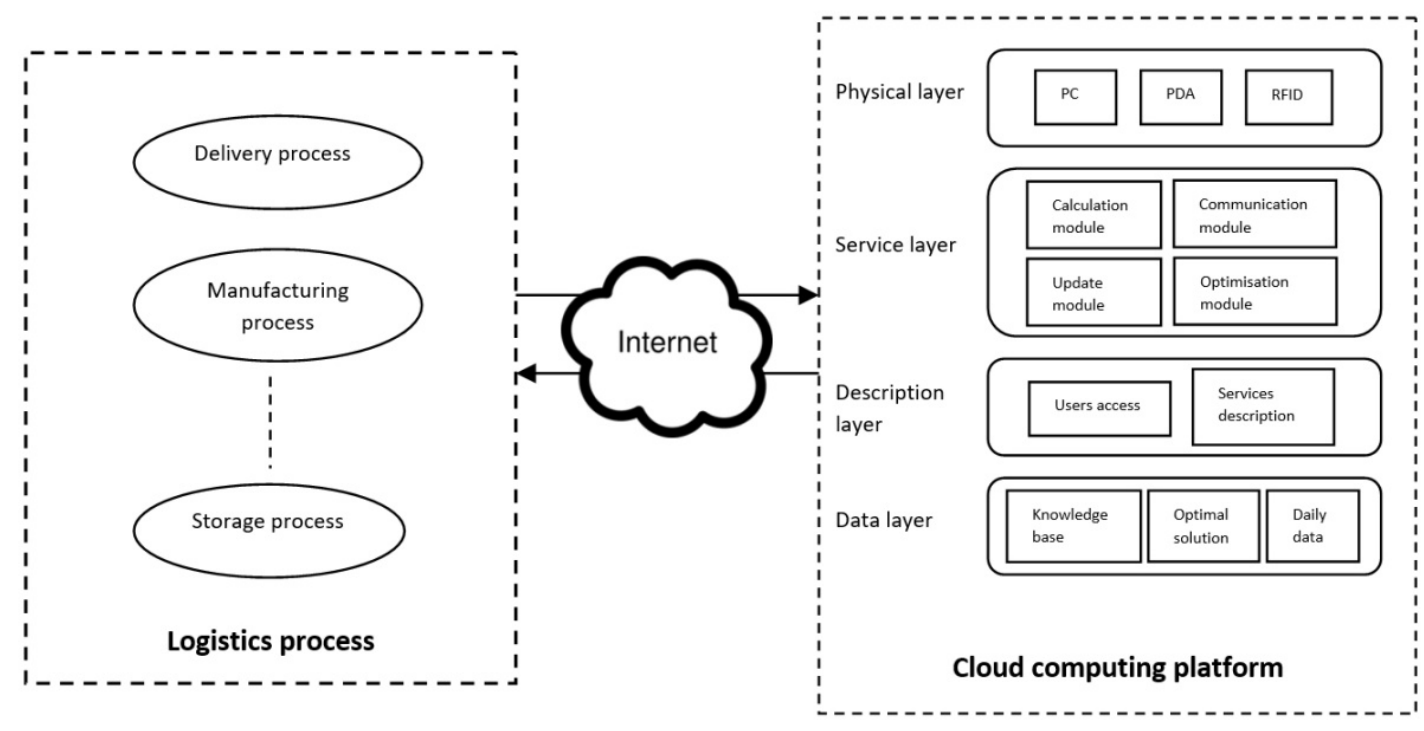

Figure 1. Cloud computing platform for logistic process

The proposed platform is composed of four layers: A physical layer, service layer, description layer and data layer.

Physical Layer: The employee, the decision-maker and the customer can communicate with the system using a PDA, a smart phone or a laptop; this enables to powering the database with data, and retrieve information associated to each process. The data is entered and displayed through a web browser.

Description layer: in this layer, the user access and the different services are defined. Each user consults the progress of the current process and can intervene or add information to the database.

In other hands, web services provide quick access to information in the cloud via the Internet. In our proposed approach, the existing network environment is used to provide various services such as access to the database, the introduction of data, the transmission of information, and communication between the different modules; in this layer, the used web services are described, Table 1 shows the web services used and their functions. 
Table 1. List of used web services

\begin{tabular}{|l|l|}
\hline Web service name & Description \\
\hline SW_Retrieve_Data & Retrieves data from interfaces \\
\hline SW_Intro_Data & Entered the data in the Database \\
\hline SW_Passive_Data & Retrieves data from internal and external Databases \\
\hline SW_CM_EM & Retrieves data from the Communication module and transmits them to the Calculating module \\
\hline SW_CM_OM & Retrieves data from the Communication module and transmits them to the Optimization module \\
\hline SW_Opt & $\begin{array}{l}\text { Recovers optimization algorithms from the directory to the optimization module to execute } \\
\text { different algorithms }\end{array}$ \\
\hline SW_Up & Update the knowledge base \\
\hline
\end{tabular}

Service layer: the different web services are defined in description layer, these enable users to follow the process execution, to obtain the necessary data for the calculation, and to have knowledge of the impact of a new policy before its adoption, and this, on account of their use of XML and HTTP standards to transfer data.

From Figure 1, we observe that this layer is composed by four modules:

- Communication Module: This module ensures communication between the different users and the system and between modules. To support business processes, two main stakeholders are distinguished in our proposed model, the employee and the decisionmaker, in addition, the customer can intervene for an eventual claim: The employee's role is to execute the process and to communicate with the system, for this he is led to enter related information process and any recorded problem. This will allow the system through its various web services to: Collect process information on real-time, record the various problems and then measure and save related costs to the process. The decision maker's role is to consult overall recorded costs through periodic reports provided by the system, he can, after consultation, query the system to try a strategic solution by searching in directory of optimal algorithms. The customer may report a problem upon receipt of the product, and the decision maker can later associate his claim to one of the business process. All data are transmitted to the calculating module via SW_CM_EM service to measure process cost and the optimization module via SW_CM_OM to propose an optimal solution.

- Calculating Module: logistic process may run several times a day, this module evaluates the process execution cost.

Costs integrate the energy consumption, emission of $\mathrm{CO} 2$ and greenhouse gases. Mathematical formulas are presented in the section of the study scenario.

- Optimization Module: This module receives passive and active data via SW_CM_OM service then uses optimization algorithms available in the algorithm directory trough SW_Opt service to propose a strategic solution to the decision maker before its adoption.

- Update Module: Once a decision is retained, the new policy is entered in the knowledge base.

Data Layer: This layer is accessed to consult or recover data such as daily process information, new knowledge and optimal solution.

To calculate the process related cost, two types of data are distinguished, passive data and active data, described in Table 2. Passive data (PD) are input during the design of the system or on the Internet using the web service SW_Passive_Data, active data (AD) are those collected during the process execution (via SW_Retrieve_Data) or calculated by the Calculating module.

The functional architecture is described in Figure 2.

Because logistic is a process-oriented business, the aim of our approach is to evaluate, improve and optimize logistics processes and the idea is that if we can control the smallest entity (process), we will succeed in controlling the entire chain. Figure 3 shows the Data Flow Diagram describing the different actions and flows. 


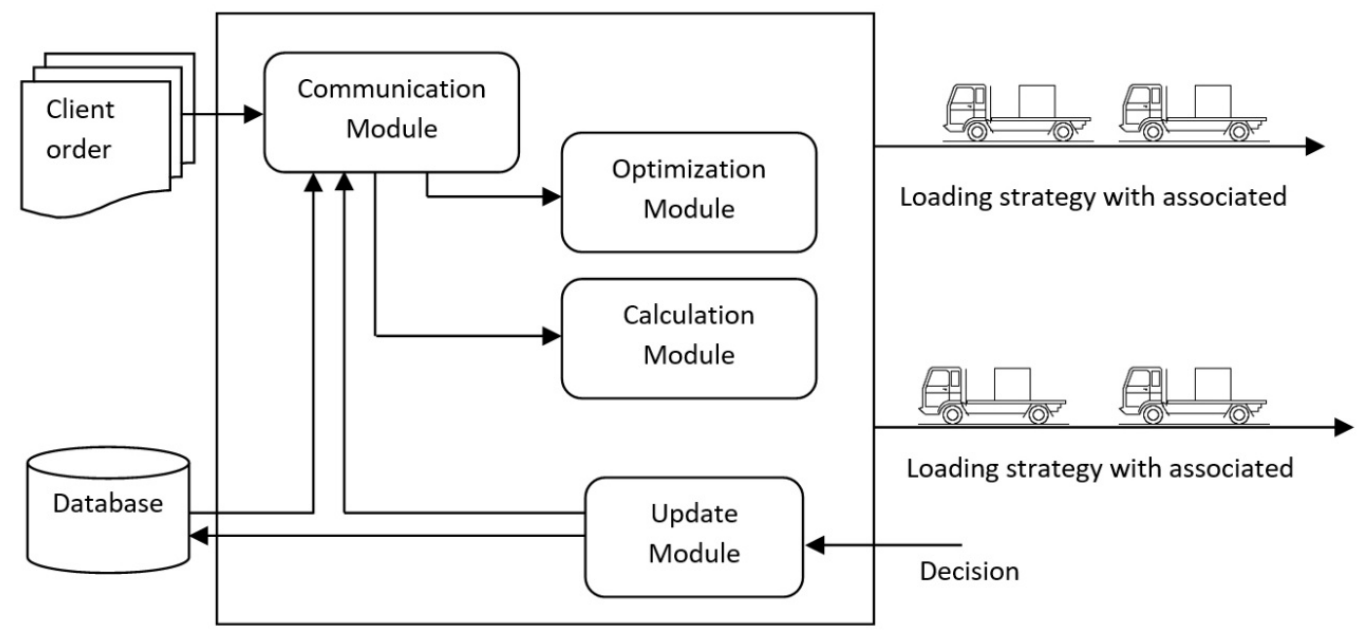

Figure 2. The functional architecture of the proposed approach

Table 2. List of passive and active data

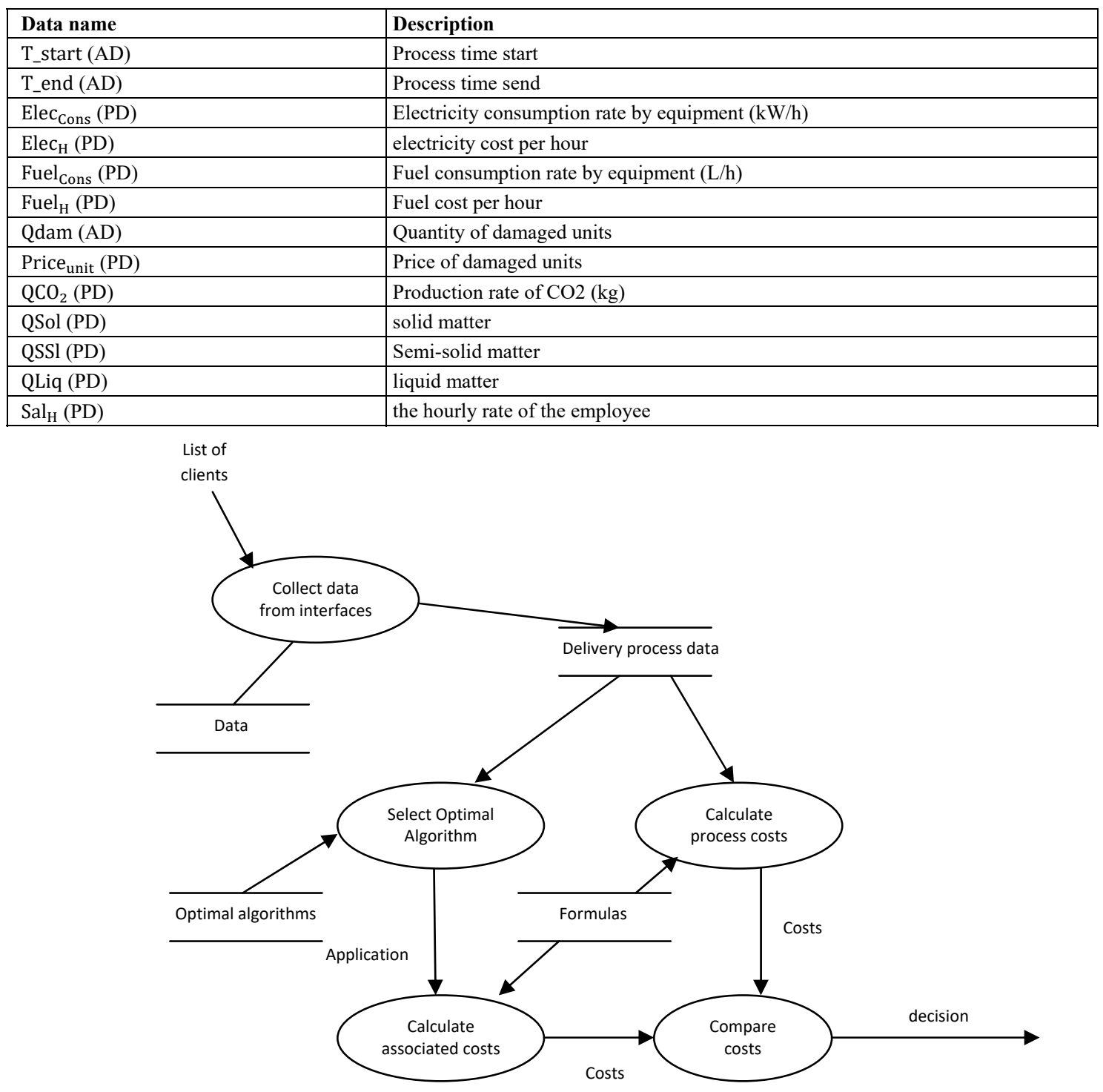

Figure 3. Data Flow Diagram of the proposed approach 


\section{Study Scenario and Problem Formulation}

The supply chain management is a complex task that is associated with decision making at all levels: from the chain design stage to its operational functioning. All these decisions will have an impact within a defined period of time. For this, three time levels with which decisions are associated are defined: strategic, tactical and operational level that will have an effect in the long, medium and short term respectively. Considering the operational decision-making level, the purpose of this scenario is to find the impact of a new policy applied to the "delivery process".

The proposed system operates as follows:

- SW_Retrieve_Data service retrieves the list of clients to be served, with the quantities ordered and transmits them to the communication module,

- Once the list recovered, $S W \_C M \_O M$ service transmits these data to the optimization module which selects the optimization algorithms from the directory via $S W$ opt, in our scenario we chose First-fit algorithm and Bin-packing algorithm for truck loading, in fact "finding the most optimal loading can reduce the cost of delivery".

- The communication module transmits the active data to the calculation module which recovers the passive data via $S W$ passive__Data and starts the calculations using the following formulas:

A process runs over duration $\mathrm{T}_{\mathrm{p}}$ (1) estimated as following:

$\mathrm{T}_{\mathrm{p}}=\mathrm{T} \_$end $-\mathrm{T} \_$start .

We consider a distance Dist $\mathrm{i}_{\mathrm{j}, \mathrm{j}}$ between $\mathrm{i}$ and $\mathrm{j}$ ( $\mathrm{i}, \mathrm{j}$ are customers or distribution centre).

The energetic cost associated to delivery process is:

$$
\text { Cost }_{1}=\text { Dist }_{i, j} * \text { Fuel }_{\text {cons }} * \text { Fuel }_{\mathrm{H}}+\alpha \mathrm{Qt}_{\mathrm{i}, \mathrm{j}} * 0.0013 * \mathrm{Fuel}_{\mathrm{H}} \text {, }
$$

with:

$\mathrm{Qt}_{\mathrm{i}, \mathrm{j}}$ is the quantity of product transported from $\mathrm{i}$ to $\mathrm{j}$.

$\alpha$ is a Boolean variable, that is equal to 1 if the vehicle is loaded, 0 - otherwise.

0.0013 represents the amount of extra fuel for a load of 1 tonne, because a vehicle consumes $15 \%$ more fuel per $100 \mathrm{~km}$ when loaded (according to several data sheets of vehicles).

In addition, an employee is remunerated for accomplishing tasks. Several employees can perform the same process, and therefore the overall salary for a given process during one execution is calculated by (3).

$$
\operatorname{Cost}_{2}=\mathrm{Nbr}^{*} \mathrm{~T}_{\mathrm{p}} * \mathrm{Sal}_{\mathrm{H}} \text {. }
$$

Therefore, economic cost associated to the "delivery process" is given by (4)

$$
\text { Cost }=\operatorname{Cost}_{1}+\operatorname{Cost}_{2}=\operatorname{NbrT}_{\mathrm{p}} \mathrm{Sal}_{\mathrm{H}}+\mathrm{Dist}_{\mathrm{i}, \mathrm{j}} * \mathrm{Fuel}_{\mathrm{cons}} * \mathrm{Fuel}_{\mathrm{H}}+\alpha \mathrm{Qt} \mathrm{i}_{\mathrm{j}} * 0.0013 * \mathrm{Fuel}_{\mathrm{H}} \text {. }
$$

We consider for environmental cost process, the amount of $\mathrm{CO}_{2}\left(\mathrm{QCO}_{2}\right)$ generated by equipment that the process used.

\subsection{Application}

For the vehicle loading, we make the following assumptions:

- We have truck containers of 10 tons $(\mathrm{T})$ of the same type

- We have a distance matrix between the distribution centre and clients and between different clients.

- Quantity is expressed in tons (T)

- Table 3 are retained values for different calculations.

Table 3. Values for calculations

\begin{tabular}{|l|l|}
\hline \multicolumn{1}{|c|}{ Data name } & Value \\
\hline Fuel $_{\text {Cons }}$ & $9 \mathrm{~L} / 100 \mathrm{Km}$ \\
\hline Fuel $_{\mathrm{H}}$ & 1.27 euro \\
\hline $\mathrm{Sal}_{\mathrm{H}}$ & 15 euro \\
\hline $\mathrm{T}_{\mathrm{p}}$ & 1 hour for each $100 \mathrm{Km}$ \\
\hline
\end{tabular}


The decision maker loads the list of customers with different quantities of products, we consider the following example, with "Ci: Vi" means "Customer i: associated quantity in tons), (see Table 4).

Table 4. Customers and quantities

\begin{tabular}{|l|l|l|l|l|l|l|l|l|l|}
\hline $\mathrm{C} 1: 2 \mathrm{~T}$ & $\mathrm{C} 2: 7 \mathrm{~T}$ & $\mathrm{C} 3: 5 \mathrm{~T}$ & $\mathrm{C} 4: 10 \mathrm{~T}$ & $\mathrm{C} 5: 9 \mathrm{~T}$ & $\mathrm{C} 6: 2 \mathrm{~T}$ & $\mathrm{C} 7: 7 \mathrm{~T}$ & $\mathrm{C} 8: 2 \mathrm{~T}$ & $\mathrm{C} 9: 4 \mathrm{~T}$ & $\mathrm{C} 10: 2 \mathrm{~T}$ \\
\hline $\mathrm{C} 11: 1 \mathrm{~T}$ & $\mathrm{C} 12: 8 \mathrm{~T}$ & $\mathrm{C} 13: 3 \mathrm{~T}$ & $\mathrm{C} 14: 7 \mathrm{~T}$ & $\mathrm{C} 15: 8 \mathrm{~T}$ & $\mathrm{C} 16: 6 \mathrm{~T}$ & $\mathrm{C} 17: 1 \mathrm{~T}$ & $\mathrm{C} 18: 2 \mathrm{~T}$ & $\mathrm{C} 19: 6 \mathrm{~T}$ & $\mathrm{C} 20: 4 \mathrm{~T}$ \\
\hline
\end{tabular}

Optimization module, through $S W$-Opt, selected and load from the directory two solutions: first-fit algorithm (Bays, 1977) and modified bin-packing algorithm.

\subsubsection{First-Fit algorithm application}

This algorithm place products according to the first of the list, until it fills the trucks, the result is:

Truck $1 \leftarrow 2 \mathrm{~T}+7 \mathrm{~T}+1 \mathrm{~T}$; so truck 1 will serve customers $\mathrm{C} 1, \mathrm{C} 2, \mathrm{C} 11$

Truck $2 \leftarrow 5 \mathrm{~T}+2 \mathrm{~T}+2 \mathrm{~T}+1 \mathrm{~T}$; so truck 2 will serve customers $\mathrm{C} 3, \mathrm{C} 6, \mathrm{C} 8$

Truck $3 \leftarrow 10 \mathrm{~T}$; so truck 3 will serve customers $\mathrm{C} 4$

Truck $4 \leftarrow 9 \mathrm{~T}$; so truck 4 will serve customers C5

Truck $5 \leftarrow 7 \mathrm{~T}+2 \mathrm{~T}$; so truck 5 will serve customers $\mathrm{C} 7, \mathrm{C} 10$

Truck $6 \leftarrow 4 \mathrm{~T}+3 \mathrm{~T}+2 \mathrm{~T}$; so truck 6 will serve customers C9. C13, C18

Truck $7 \leftarrow 8 \mathrm{~T}$; so truck 7 will serve customers $\mathrm{C} 12$

Truck $8 \leftarrow 7 \mathrm{~T}$; so truck 8 will serve customers $\mathrm{C} 14$

Truck $9 \leftarrow 8 \mathrm{~T}$; so truck 9 will serve customers C15

Truck $10 \leftarrow 6 \mathrm{~T}+4 \mathrm{~T}$; so truck 10 will serve customers C16, C20

Truck $11 \leftarrow 6 \mathrm{~T}$; so truck 11 will serve customers C19

We note that 11 Trucks were used, and according to Formulas 4, the corresponding economic cost for Truck 1 for example, is:

$$
\begin{aligned}
& \text { Cost }=\text { Dist }_{\mathrm{D}, \mathrm{Cl}} * \text { Fuel }_{\text {cons }} * \mathrm{Fuel}_{\mathrm{H}}+\alpha \mathrm{Qt}_{\mathrm{D}, \mathrm{Cl}} * \text { Dist }_{\mathrm{D}, \mathrm{Cl}} * 0.0013 * \mathrm{Fuel}_{\mathrm{H}}+\text { Dist }_{\mathrm{Cl}, \mathrm{C} 2} * \mathrm{Fuel}_{\text {cons }} * \mathrm{Fuel}_{\mathrm{H}} \\
& +\alpha \mathrm{Qt}_{\mathrm{Cl}, \mathrm{C} 2} * \text { Dist }_{\mathrm{Cl}, \mathrm{C} 2} * 0.013 * \mathrm{Fuel}_{\mathrm{H}}+\text { Dist }_{\mathrm{C} 2, \mathrm{C} 11} * \mathrm{Fuel}_{\text {cons }} * \mathrm{Fuel}_{\mathrm{H}} \\
& +\alpha \mathrm{Qt}_{\mathrm{C} 2, \mathrm{C} 11} * \text { Dist }_{\mathrm{C} 2, \mathrm{C} 11} * 0.0013 * \mathrm{Fuel}_{\mathrm{H}}
\end{aligned}
$$

From (5), $Q t_{D, C 1}$ is the quantity transported from the deposit $\mathrm{D}$ to the customer $\mathrm{C} 1$, and it is equal to the total load.

$\mathrm{Qt}_{\mathrm{C} 1, \mathrm{C} 2}$ is the quantity transported from the customer $\mathrm{C} 1$ to the customer $\mathrm{C} 2$, and it is equal to the total load less the quantity delivered to the client $\mathrm{C} 1$.

Total economic cost for this scenario is estimated at 1056.33 euro

According to the methodological guide of Transport Code (Guide, 2012), the consumption of 1 litter of fuel causes $3.07 \mathrm{~kg}$ of CO2 production. Total quantity of CO2 in our scenario is $1059 \mathrm{Kg}$.

Currently, more and more countries start to introduce binding standards for vehicle emissions. We put, for example, a penalty of 95 euro for the production of 100 grams of CO2; each truck produces $276 \mathrm{~g}$ per kilometre (0.09litter / $\mathrm{km} * 3.07 \mathrm{Kg}$ according (Guide, 2012)), so, for one truck the penalty is 262.48euro either 2887.33 euro for 11 trucks. Results are shown in Table 5.

\subsubsection{Bin-Packing application algorithm}

In the bin packing problem (Korte and Vygen, 2006), objects of different volumes must be packed into a finite number of bins or containers in a way that minimizes the number of bins used.

For the delivery process, this algorithm aims to minimize the number of used Trucks by combining different amounts of an optimal way, but in our case, we propose a bin-packing algorithm modified, which:

- Sort the quantities in each client order by descending order, in a list.

- Load the first quantity in the list.

- If the Load is mower then the vehicle size: search the quantities completing the load to size which has the Min-cost (according to Formula 4), and load it. (see the organizational chart of the modified algorithm of Figure 4) 
Table 5. Results after First-Fit application algorithm

\begin{tabular}{|c|c|c|c|}
\hline Truck & From-To & Cost (euro) & Rate of Co2 (Kg) \\
\hline \multirow[t]{3}{*}{ Truck 1} & $\mathrm{D}-\mathrm{C} 1$ & 28.08 & 27.63 \\
\hline & $\mathrm{C} 1-\mathrm{C} 11$ & 19.96 & 19.341 \\
\hline & $\mathrm{C} 11-\mathrm{C} 2$ & 53.80 & 52.497 \\
\hline \multirow[t]{4}{*}{ Truck 2} & D-C3 & 28.31 & 27.63 \\
\hline & C3-C6 & 51.34 & 49.734 \\
\hline & C6-C17 & 42.47 & 41.445 \\
\hline & $\mathrm{C} 17-\mathrm{C} 8$ & 67.96 & 66.312 \\
\hline Truck 3 & D-C4 & 28.31 & 27.63 \\
\hline Truck 4 & D-C5 & 42.47 & 41.445 \\
\hline \multirow[t]{2}{*}{ Truck 5} & D-C7 & 53.69 & 55.26 \\
\hline & $\mathrm{C} 7-\mathrm{C} 10$ & 77.02 & 74.601 \\
\hline \multirow[t]{3}{*}{ Truck 6} & D-C9 & 56.63 & 55.26 \\
\hline & C9-C13 & 84.95 & 82.89 \\
\hline & C13-C18 & 29.53 & 30.393 \\
\hline \multirow[t]{2}{*}{ Truck 7} & D-C12 & 14.15 & 13.815 \\
\hline & $\mathrm{C} 12-\mathrm{C} 18$ & 48.13 & 46.971 \\
\hline Truck 8 & D-C14 & 79.87 & 77.364 \\
\hline Truck 9 & D-C15 & 56.63 & 55.26 \\
\hline \multirow[t]{2}{*}{ Truck 10} & D-C16 & 16.23 & 16.578 \\
\hline & $\mathrm{C} 16-\mathrm{C} 20$ & 71.92 & 74.601 \\
\hline Truck 11 & D-C19 & 104.77 & 102.231 \\
\hline
\end{tabular}

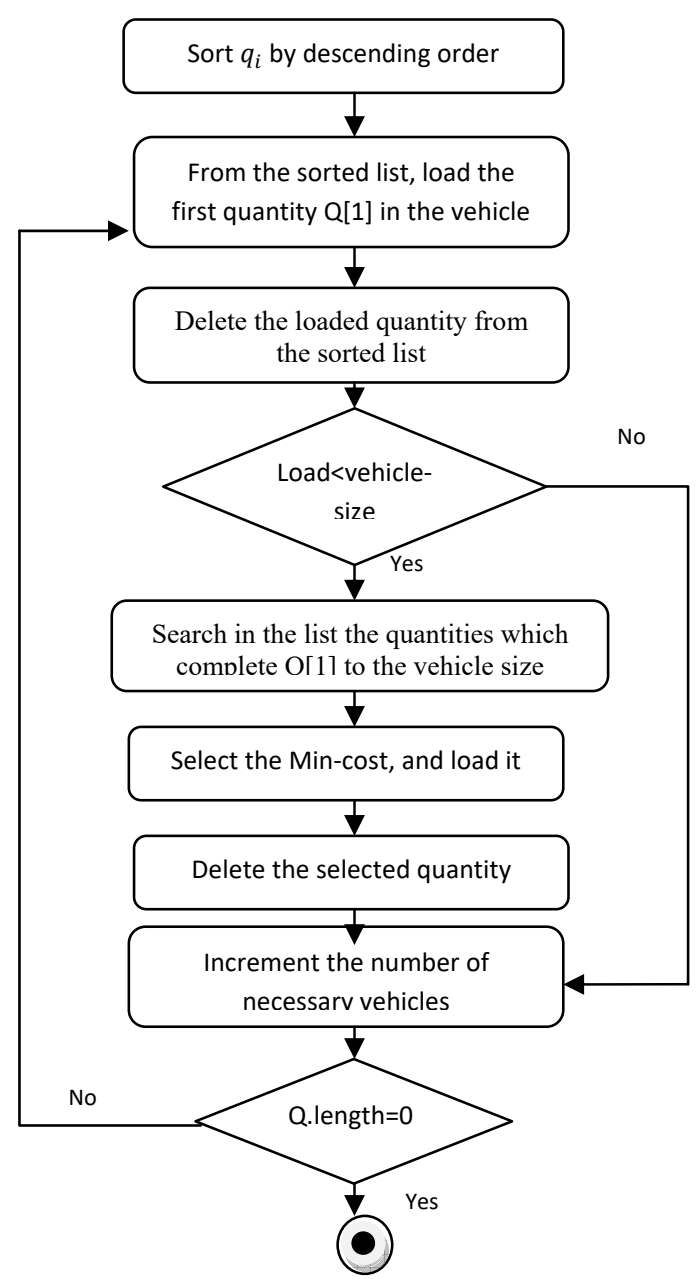

Figure 4. Organizational chart of modified Bin-Packing algorithm 
The modified algorithm is shown below in Figure 5, with:

- $\quad q_{i} \in Q[n]$ : The quantity ordered by customer $i$.

- $\quad L$ is a linked list of array $Q[n]$ with length.

- $\quad$ size is the vehicle size

- $n b$ is the number of used vehicles.

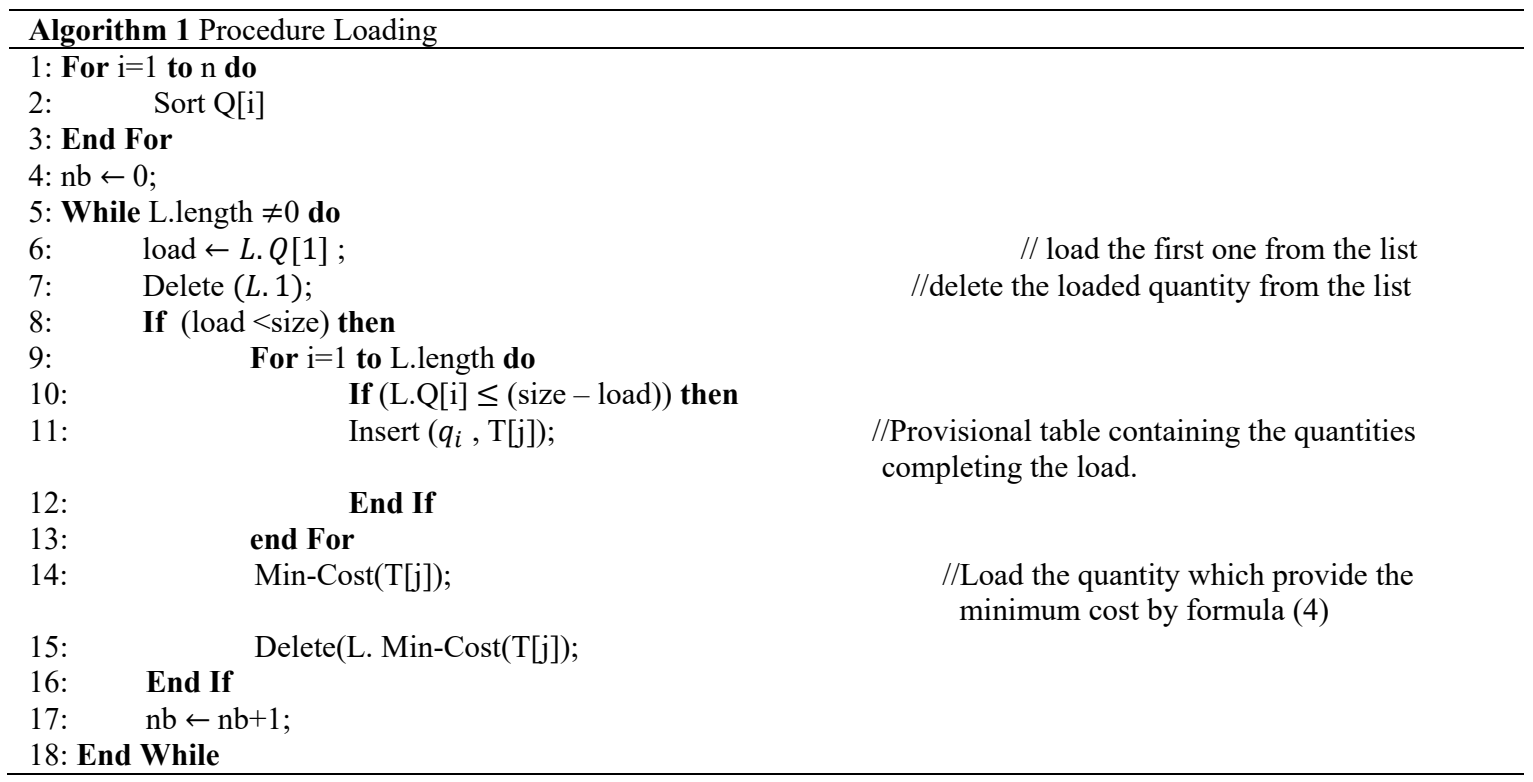

Figure 5. Algorithm 1. Modified Bin-Packing algorithm

This algorithm runs as follow:

$\mathrm{C} 4$ is affected to the first truck, because quantity commanded by $\mathrm{C} 4=10 \mathrm{~T}=\mathrm{C}$.

For $\mathrm{Q}=9 \mathrm{~T}$, corresponding customer is: $\mathrm{C} 5$, the modified algorithm searches in the list of unassigned clients, and find these two combinations:

1) C5- C11, with associated cost (6)

$$
\begin{aligned}
& \text { Costl }=\text { Dist }_{\mathrm{D}, \mathrm{C} 5} * \mathrm{Fuel}_{\text {cons }} * \mathrm{Fuel}_{\mathrm{H}}+\alpha \mathrm{Qt}_{\mathrm{D}, \mathrm{C} 5} * \mathrm{Dist}_{\mathrm{D}, \mathrm{C} 5} * 0.0013 * \mathrm{Fuel}_{\mathrm{H}} \\
& + \text { Dist }_{\mathrm{C} 5, \mathrm{C} 11} * \mathrm{Fuel}_{\mathrm{cons}} * \mathrm{Fuel}_{\mathrm{H}}+\alpha \mathrm{Qt}_{\mathrm{C} 5, \mathrm{C} 11} * \mathrm{Dist}_{\mathrm{C} 5, \mathrm{C} 11} * 0.0013 * \mathrm{Fuel}_{\mathrm{H}}=184.37 \text { euro }
\end{aligned}
$$

2) $\mathrm{C} 5-\mathrm{C} 17$ the associated cost is (7):

$$
\begin{aligned}
& \text { Cost }=\text { Dist }_{\mathrm{D}, \mathrm{C} 5} * \mathrm{Fuel}_{\text {cons }} * \mathrm{Fuel}_{\mathrm{H}}+\alpha \mathrm{Qt}_{\mathrm{D}, \mathrm{C} 5} * \mathrm{Dist}_{\mathrm{D}, \mathrm{C} 5} * 0.0013 * \mathrm{Fuel}_{\mathrm{H}} \\
& +\mathrm{Dist}_{\mathrm{C} 5, \mathrm{C} 17} * \mathrm{Fuel}_{\mathrm{cons}} * \mathrm{Fuel}_{\mathrm{H}}+\alpha \mathrm{Qt}_{\mathrm{C} 5, \mathrm{C} 117} * \mathrm{Dist}_{\mathrm{C} 5, \mathrm{C} 17} * 0.0013 * \mathrm{Fuel}_{\mathrm{H}}=116.41 \text { euro }
\end{aligned}
$$

The minimum (Cost1, Cost2) is Cost2, so the algorithm choose to retain C17. Table 6 shows the entire calculation.

As we saw from Table 6, the colored cells are those having the minimum cost, and therefore the catching is done in the following manner:
Truck 1: $\mathrm{C} 4$
Truck2: $\mathrm{C} 5-\mathrm{C} 17$
Truck3: C12-C1
Truck 4: C15-C6
Truck 5: C2-C13
Truck 6: C7-C8-C11
Truck 7: C14-C18
Truck 8:C16-C10
Truck 9: C19-C20
Truck 10: C3-C9 
We note that 10 Trucks were used, and total economic cost for this scenario is estimated at 966.01 euro.

Table 6. Results after modified Bin-Packing application algorithm

\begin{tabular}{|c|c|c|c|}
\hline Truck & From-To & Cost (euro) & Rate of Co2 (Kg) \\
\hline truck1 & D-C4 & 28.081 & 27.63 \\
\hline \multirow[t]{3}{*}{ truck 2} & D-C5 & 42.790155 & 41.445 \\
\hline & $\mathrm{C} 5-\mathrm{C} 11$ & 141.585465 & 138.15 \\
\hline & $\mathrm{C} 5-\mathrm{C} 17$ & 73.6244418 & 71.838 \\
\hline \multirow[t]{6}{*}{ truck 3} & D-C12 & 14.263385 & 13.815 \\
\hline & $\mathrm{C} 12-\mathrm{C} 1$ & 42.4756395 & 41.445 \\
\hline & $\mathrm{C} 12-\mathrm{C} 6$ & 84.951279 & 82.89 \\
\hline & $\mathrm{C} 12-\mathrm{C} 10$ & 50.9707674 & 49.734 \\
\hline & $\mathrm{C} 12-\mathrm{C} 8$ & 50.9707674 & 49.734 \\
\hline & C12-C18 & 45.6439018 & 46.971 \\
\hline \multirow[t]{5}{*}{ truck 4} & D-C15 & 57.05354 & 55.26 \\
\hline & $\mathrm{C} 15-\mathrm{C} 18$ & 141.585465 & 93.942 \\
\hline & C15-C6 & 16.1096124 & 16.578 \\
\hline & C15-C8 & 141.585465 & 138.15 \\
\hline & $\mathrm{C} 15-\mathrm{C} 10$ & 107.604953 & 104.994 \\
\hline \multirow[t]{8}{*}{ truck 5} & D-C2 & 42.790155 & 41.445 \\
\hline & $\mathrm{C} 2-\mathrm{C} 13$ & \begin{tabular}{|l|}
73.6244418 \\
\end{tabular} & 71.838 \\
\hline & $\mathrm{C} 2-\mathrm{C} 10$ & 67.6475775 & 69.075 \\
\hline & $\mathrm{C} 10-\mathrm{C} 11$ & 13.3198385 & 13.815 \\
\hline & $\mathrm{C} 2-\mathrm{C} 8$ & 79.2878604 & 52.497 \\
\hline & $\mathrm{C} 8-\mathrm{C} 11$ & 73.6244418 & 71.838 \\
\hline & $\mathrm{C} 2-\mathrm{C} 18$ & 175.883702 & 49.734 \\
\hline & C18-C11 & 119.878547 & 19.341 \\
\hline \multirow[t]{7}{*}{ truck 6} & D-C7 & 53.279354 & 22.104 \\
\hline & C7-C8 & 17.116062 & 16.578 \\
\hline & C8-C11 & 74.169602 & 49.734 \\
\hline & $\mathrm{C} 7-\mathrm{C} 10$ & 77.022279 & 74.601 \\
\hline & C10-C11 & 14.263385 & 33.156 \\
\hline & C7-c18 & 19.968739 & 52.497 \\
\hline & $\mathrm{C} 18-\mathrm{C} 11$ & 128.370465 & 102.231 \\
\hline \multirow[t]{3}{*}{ truck7 } & D-C14 & 79.2878604 & 30.393 \\
\hline & $\mathrm{C} 14-\mathrm{C} 10$ & 141.585465 & 82.89 \\
\hline & C14-C18 & 56.3836434 & 52.497 \\
\hline \multirow[t]{4}{*}{ truck 8} & D-C16 & 16.9902558 & 77.364 \\
\hline & C16-C9 & 49.0836744 & 138.15 \\
\hline & C16-C20 & 76.4561511 & 96.705 \\
\hline & $\mathrm{C} 16-\mathrm{C} 10$ & 33.9805116 & 27.63 \\
\hline \multirow[t]{3}{*}{ truck 9} & D-C19 & 105.549049 & 96.705 \\
\hline & C19-C20 & 29.9955788 & 25.549 \\
\hline & C19-C9 & 116.100081 & 105.521 \\
\hline \multirow[t]{2}{*}{ truck 10} & D-C3 & 27.897739 & 26.324 \\
\hline & C3-C9 & 80.548062 & 79.486 \\
\hline
\end{tabular}

The Environmental cost:

In this scenario, we calculate the rate of $\mathrm{CO} 2$, from methodological guide of Transport Code (Guide, 2012), the consumption of 1 litter of fuel causes $3.07 \mathrm{~kg}$ of CO2 production. The total quantity of $\mathrm{CO} 2$ is $903.5 \mathrm{Kg}$.

The penalty of production of $\mathrm{CO} 2$ for 10 trucks is estimated at 2624 euro. 


\subsection{Comparison}

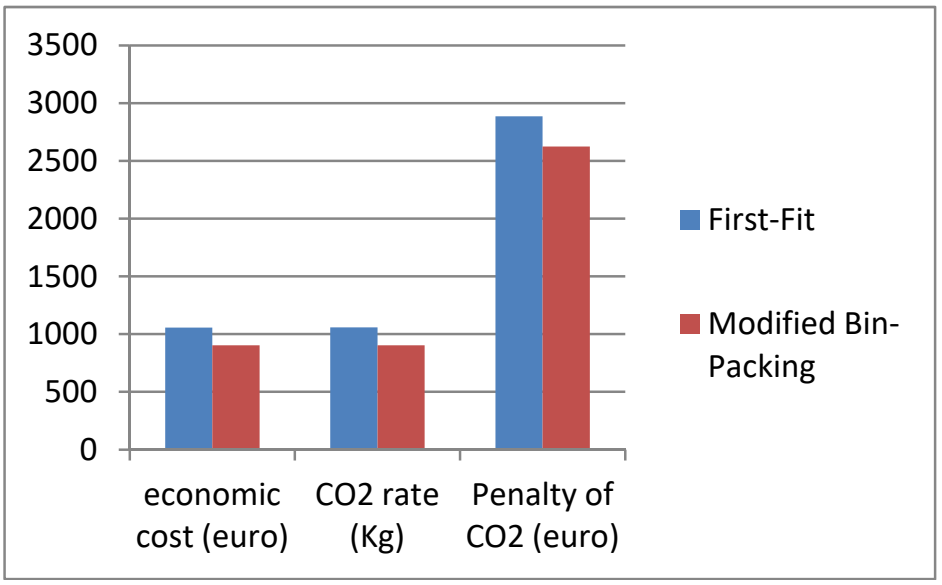

Figure 6. Comparison of results

The results of two algorithms comparing are presented on Figure 6. As shown in economic and environmental terms the Bin-Packing modified algorithm gives better results than the First-Fit algorithm with a gain of:

- $\quad 90,20$ euro in economic cost;

- $156 \mathrm{~kg}$ of $\mathrm{CO} 2$ production;

- $\quad 163.3$ euro of $\mathrm{CO} 2$ production penalty.

These results show that sorting and finding the right load complement with minimal cost can reduce the costs associated with the process; because the algorithm chooses to load the vehicle with the least expensive customer orders in economic and energy terms.

\section{Conclusion}

The principle of supply chain management is to deliver "the right product in the right quantity to the right place at the right time and with minimal cost" (Neven, 1989). To achieve this, the company must adopt a good logistics chain management policy whose main objective is to increase the overall gain by maximizing profits and minimizing costs, including manufacturing, transaction, Transportation, storage, etc. This is associated to decision making at all levels: from the chain design stage to its operational functioning. All these decisions will have an impact within a defined period of time. This is why, three time levels with which decisions are associated are defined: strategic, tactical and operational level that will have an effect in the long, medium and short term respectively. Considering the operational decisionmaking level, we have proposed in this paper a cloud platform of chain logistics for decision support; in fact, decisions must be made to adopt or not a new strategies for cost optimization, however, the decisionmaker must have knowledge on the consequences of this new strategy.

Our proposed cloud computing platform has a multilayer structure, it is composed of a set of web services to provide a link between applications using different technologies and to enable sending and receiving of data through protocols understandable by everyone.

Integration of cloud computing services for logistics offers new benefits to companies such as access to resources on demand, elasticity and usage billing. Our proposed approach allowed through its multilayer structure assisted by web services, to estimate the economic and environmental costs of a logistic process; this provides a decision-support for evaluating a decision before its application. As scenario, we formulated the problem for the delivery process, and we proposed a modified Bin-Packin algorithm for vehicle loading. Results show that in economic and environmental terms, the Bin-packing modified algorithm gives better results than the First-fist algorithm. For future work, we will try to integrate a data mining module for the proposed decisions, we also propose generalizing the work for other logistic processes. 


\section{References}

1. Abduaziz, O., Cheng, J.K., Tahar R.M. and Varma, R. (2014) A hybrid Simulation model for Green Logistics Assessment in Automotive Industry. In: the 25th International Symposium on Intelligent Manufacturing and Automation, DAAAM, 2014. Vienna, Austria: Procedia Engineering, pp. 960-961.

2. Bays, C. (1977) A comparison of next-fit, first-fit, and best-fit. Commun. ACM, Volume 20(3), pp. 191-192.

3. Boukherroub, T., Ruiz, A., Guinet, .A and and Fondrevelle, J. (2015) An integrated approach for sustainable supply chain planning. Computers \& Operations Research, 54, pp. 180-194.

4. Carrera, S., Portmann, M.C. and Ramdane Cherif, W. (2010a) Scheduling problems for logistic platforms with fixed staircase component arrivals and various deliveries hypotheses. In: Lecture Notes in Management Science, Proceedings of the 2th International Conference on Applied Operational Research - ICAOR, Turku, Finlande, pp. 517-528.

5. Carrera, S., Portmann, M.C. and Ramdane Cherif, W. (2010b) Scheduling supply chain node with fixed components arrivals and two partially flexible deliveries. In: 5th International Conference on Management and Control of Production and Logistics - MCPL 2010, Sep 2010, Coimbra, Portugal. IFAC Publisher, pp. 6, 2010 MCPL, Coimbra, Portugal.

6. Chow, H.K.L., Choy, K.L. and Lee, W.B. (2007) A dynamic logistics process knowledge-based system - An RFID multi-agent approach. Knowledge-Based Systems, 20(4), pp. 357-372.

7. Daniluk, D. and Holtkamp, B. (2014) Logistics Mall: A Cloud Platform for Logistics. Hompel, M., Rehof, J. and Wolf, O. Editors, Lecture Notes in Logistics, Springer, pp. 13-27.

8. David, R., Gnimpieba, Z., Nait-Sidi-Moh, A., Durand, D. and Fortin, J. (2015) Vehicle routing problem with time-windows for perishable food delivery. In: The 12th International Conference on Mobile Systems and Pervasive Computing, Belfort, France.

9. Guide méthodologique (2012), Information CO2 des prestations de transport. Application de 1'article L. 1431-3 du code des transports. (In French)

10. Holtkamp, B. (2014) The Logistics Mall: An IT-Architecture for Logistics-as-a-Product. Hompel, M., Rehof, J. and Wolf, O. Editors, Lecture Notes in Logistics, Springer, pp. 45-62.

11. Korte, B. Vygen, J. (2006) Combinatorial Optimization: Theory and Algorithms. Algorithms and Combinatorics. Springer. pp. 426-441.

12. Li, X., Wang, Y. and Chen, X. (2012) Cold chain logistics system based on cloud computing, Concurrency Computat. Practice and Experience, 24(17), pp. 2138-2150.

13. Nettstrater, A., Geiben, T., Witthaut, M., Ebel, D. and Schoneboom, J. (2014) Logistics Software Systems and Functions: An Overview of ERP, WMS, TMS and SCM Systems. Hompel, M., Rehof, J. and Wolf, O. Editors, Lecture Notes in Logistics, Springer, pp.1-11.

14. Neven Workgroupe (1989) Performance indicators in logistics. Technical report, IFS Publication, Springer-Verlag.

15. Subramanian, N., Abdulrahman, M.D., and Zhou, X. (2014) Integration of logistics and cloud computing service providers: Cost and green benefits in the Chinese context. Transportation Research Part E: Logistics and Transportation Review, 70, pp. 86-98. 